\title{
Mathematical Simulation of Tungsten Carbide Machining Using Finite Elements Method
}

\author{
Jozef Zajac $^{1}$, Svetlana Radchenko ${ }^{1}$, Zuzana Mital’ová ${ }^{1}$, PavolBeraxa ${ }^{1,2}$, JánDuplák ${ }^{1}$, Peter Čižmár \\ \{jozef.zajac@tuke.sk, svetlana.radchenko@tuke.sk, zuzana.mitalova@tuke.sk\} \\ Technical University of Kosice, Faculty of Manufacturing Technologies with a seat in Presov, \\ Bayerova 1, 08001 Presov $^{1}$ \\ ŽP VVC, s.r.o., Kolkáreň 35,976 81 Podbrezová, Slovakiaª
}

\begin{abstract}
Presented article is focused simulation and visualization of the turning process of hard metal material. The main purpose is to describe the phenomena occurring during the process of chip machining in various cutting conditions. In this work, simulation software is used to analyze an actual process of the simulation and its concomitant circumstances. The use of modeling and simulation software is cost and time efficient. The article is divided into two main parts. The first part focuses on characterization and description of the turning process. The second part concentrates on explanation and simulation of the chip machining process of hard metal material by means of FEM analysis software.
\end{abstract}

Keywords: simulation, FEM, machining, workpiece

\section{Introduction}

Turning belongs between most wide spread technologies of chip machining. This lead to necessity of instant improving of mentioned machining process. Important factors are decreasing of operating costs, shortening of production time, increasing of surface quality and dimensional accuracy, increasing of tools durability and many others. Presented article is focused on simulation and visualization of turning of hard metal workpiece based on FEM analysis. Simulation process is created to analyze several machining conditions for selected material [1].

\section{Technological conditions and material properties}

Input values are very important for successful simulation with appropriate results which are applicable in practical conditions. Input factors used in presented simulation were cutting speed $v_{c}\left[\mathrm{~m} \cdot \mathrm{min}^{-1}\right]$, feed rate $f[\mathrm{~mm} / \mathrm{rev}]$, depth of cut $a_{p}[\mathrm{~mm}]$, initial temperature $\left[{ }^{\circ} \mathrm{C}\right]$. Following parameters were selected tool geometry, material of tool, material of workpiece [1], [2]. 
Machining conditions used for simulation were as listed below:

Workpiece material: CTE 60M

Cutting plates: CBN (diameter 12,6 mm)

\section{Roughing}

New cutting plates:

Cutting speed: $\quad v_{c}=75 \mathrm{~m} \cdot \mathrm{min}^{-1}$

Feed rate: $\quad f=0,25 \mathrm{~mm} / \mathrm{rev}$

Depth of cut: $\quad a_{p}=\max .1,0 \mathrm{~mm}$

For used cutting plates:

Cutting speed: $\quad v_{c}=65 \mathrm{~m} \cdot \mathrm{min}^{-1}$

Feed rate: $\quad f=0,30 \mathrm{~mm} / \mathrm{rev}$

Depth of cut: $\quad a_{p}=\max .1,0 \mathrm{~mm}$

\section{Finishing}

Finishing operation is performed exclusively using new never used cutting plates.

Cutting speed: $\quad v_{c}=80 \mathrm{~m} \cdot \mathrm{min}^{-1}$

Feed rate: $\quad f=0,20 \mathrm{~mm} / \mathrm{rev}$.

Depth of cut: $\quad a_{p}=\max .0,5 \mathrm{~mm}$

Table 1. Mechanical properties of CTE 60M

\begin{tabular}{|l|r|}
\hline Hardness HV 10 & 610 \\
\hline Elasticity modulus [GPa] & 420 \\
\hline Fracture toughness $\left[\mathrm{MPa} / \mathrm{m}^{2}\right]$ & 29,0 \\
\hline Compressive parameter $[\mathrm{MPa}]$ & 3000 \\
\hline Density $\left[\mathrm{kg} / \mathrm{m}^{3}\right.$ ] & 12,70 \\
\hline Thermal conductivity $[\mathrm{W} / \mathrm{mK}]$ & 95 \\
\hline
\end{tabular}

Table 2. Properties of CBN material

\begin{tabular}{|l|r|}
\hline Knoop hardness [GPa] & $55-60$ \\
\hline Elasticity modulus [GPa] & $500-550$ \\
\hline Critical load [N] & 25 \\
\hline Density [g/cm ${ }^{3}$ ] & 3,45 \\
\hline
\end{tabular}

Mesh can be generated on both tool and workpiece after all necessary parameters are set. On following figures are shown selected tool (Figure 1.) and workpiece and generated mesh (Figure 2.) [4], [5].

Boundary conditions have to be set for both tool and workpiece due to mutual interaction. Workpiece is bonded in all axes $\mathrm{x}, \mathrm{y}, \mathrm{z}$ due to machining simulation stability. Heat transfer is selected for interaction between tool and workpiece and environment. Starting temperature was set to $20^{\circ} \mathrm{C}$ [2], [3], [7]. 


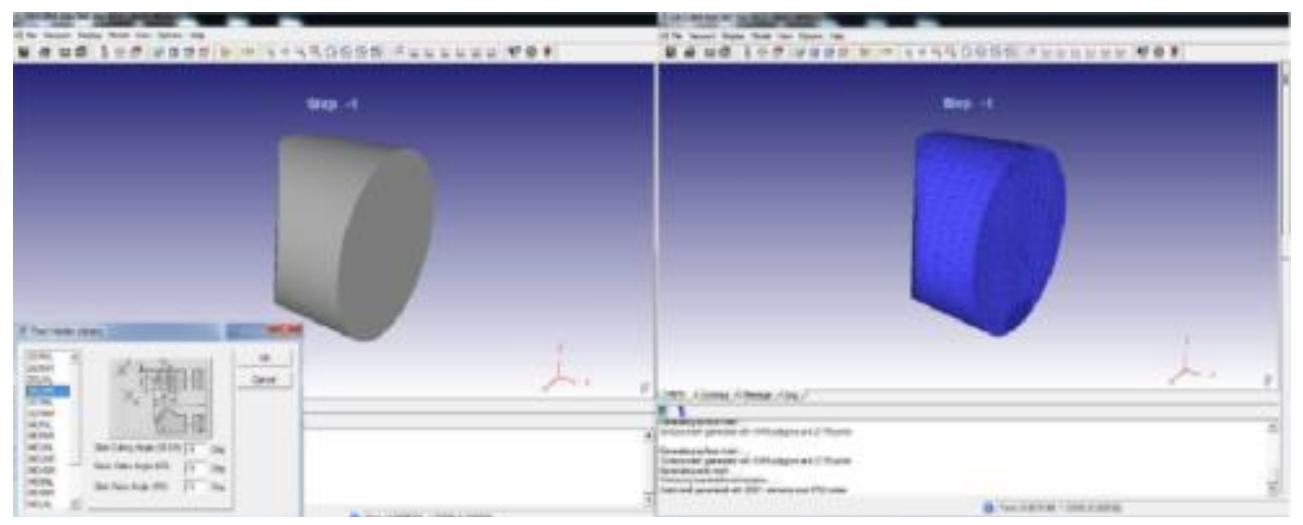

Fig. 1. CBN tool and finite elements mesh

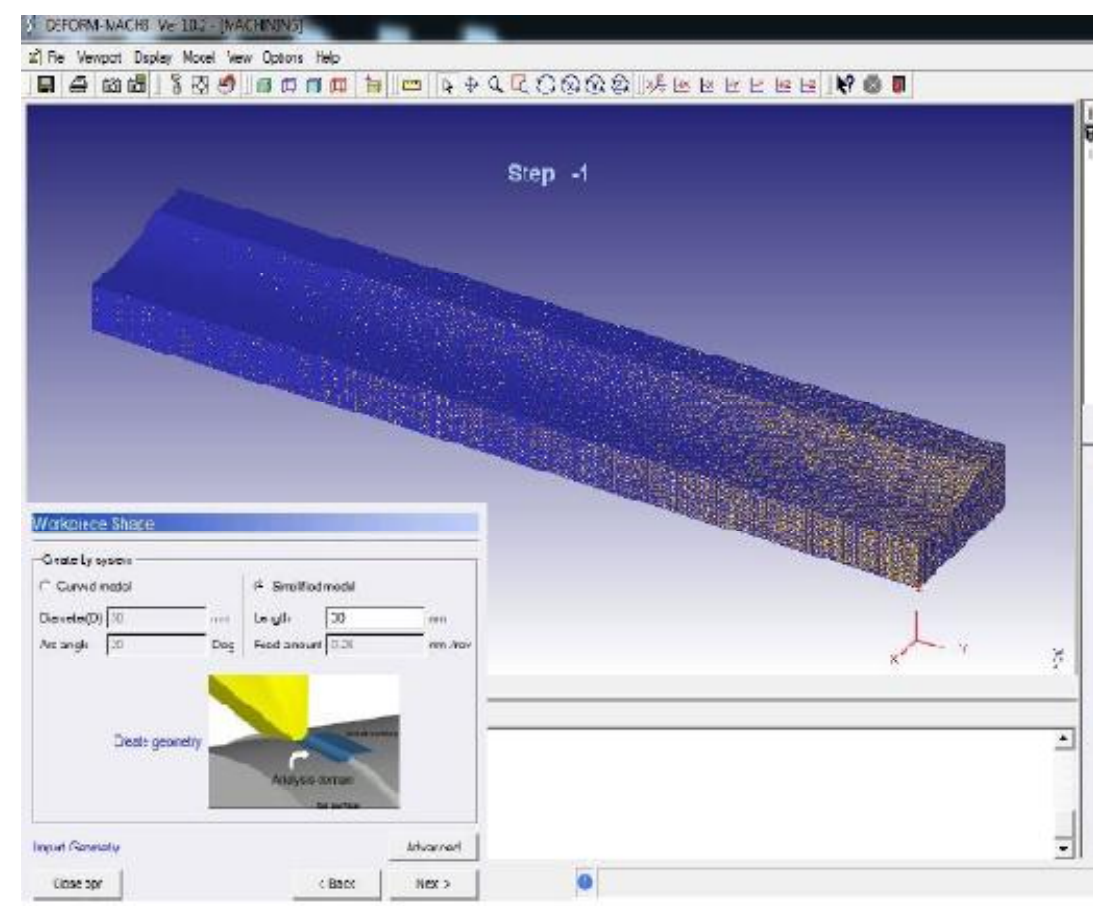

Fig. 2. Simplified model of workpiece

\section{Simulation}

Machining process is divided to 1850 steps. Tool wear is calculated using Usui method based on equation (1) [6], [8]:

$$
w=\int a \cdot p \cdot V \cdot e^{-b t}
$$


Where:

$a, b$-experimental coefficients [-]

$p$ - pressure $[\mathrm{Pa}]$

$t$ - temperature $\left[{ }^{\circ} \mathrm{C}\right]$

$v-$ speed $\left[\mathrm{m} . \mathrm{s}^{-1}\right]$

Strain - effective- sheer strain was observed in four stages. On following figure (Figure 3.) are displayed values of sheer strain for steps 650, 900, 1250 and 1850 .

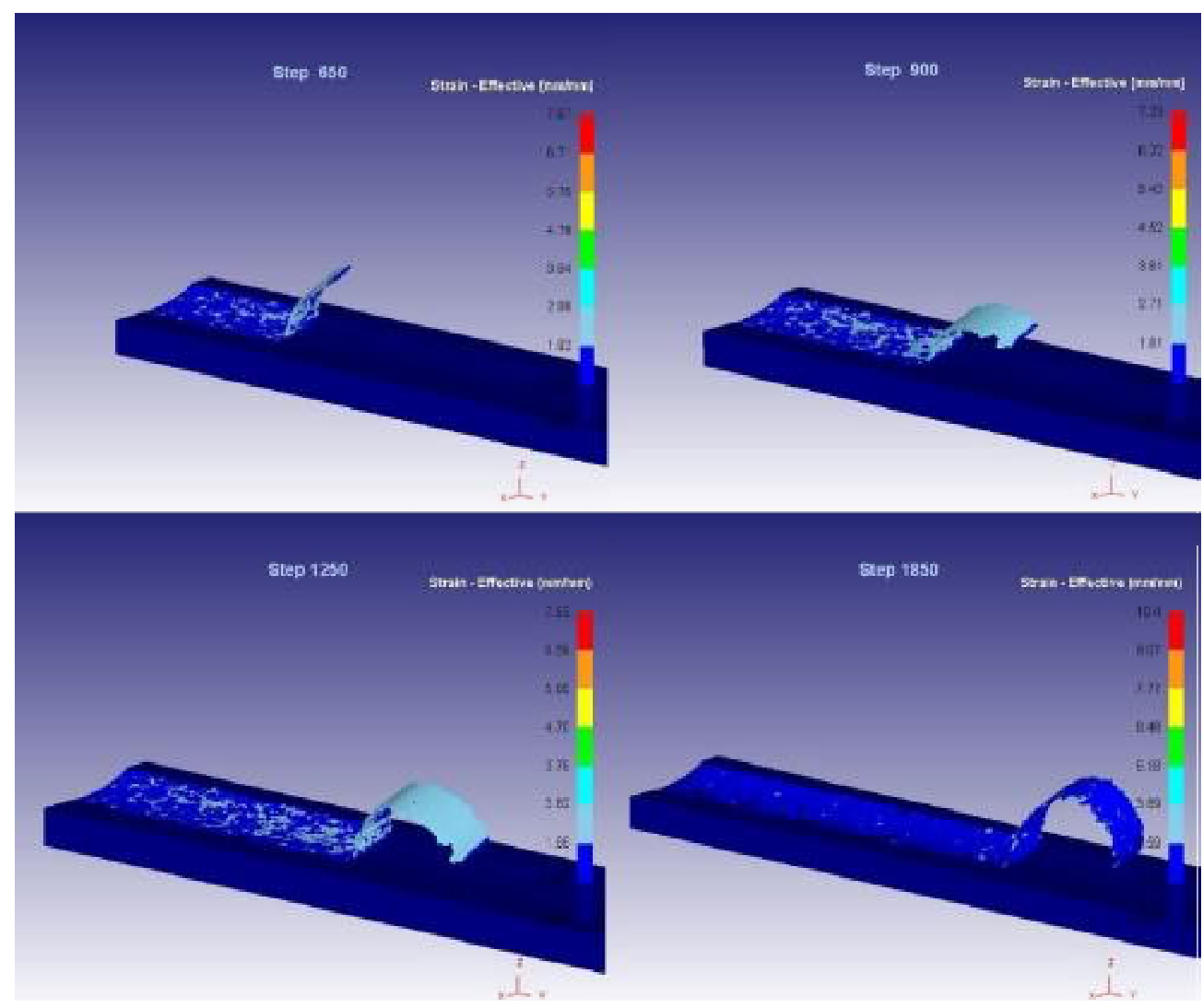

Fig. 3.Strain effective

Damage - is used to predict fracture in every step of simulation. Damage is defined by damage factor. Damage factor is defined by equation (2):

$$
D f=\int \sigma+/ \sigma d \epsilon
$$

Where:

$\sigma+$ - maximum tensile principal stress

$\sigma$ - effective stress

$d \epsilon$ - effective strain increment 


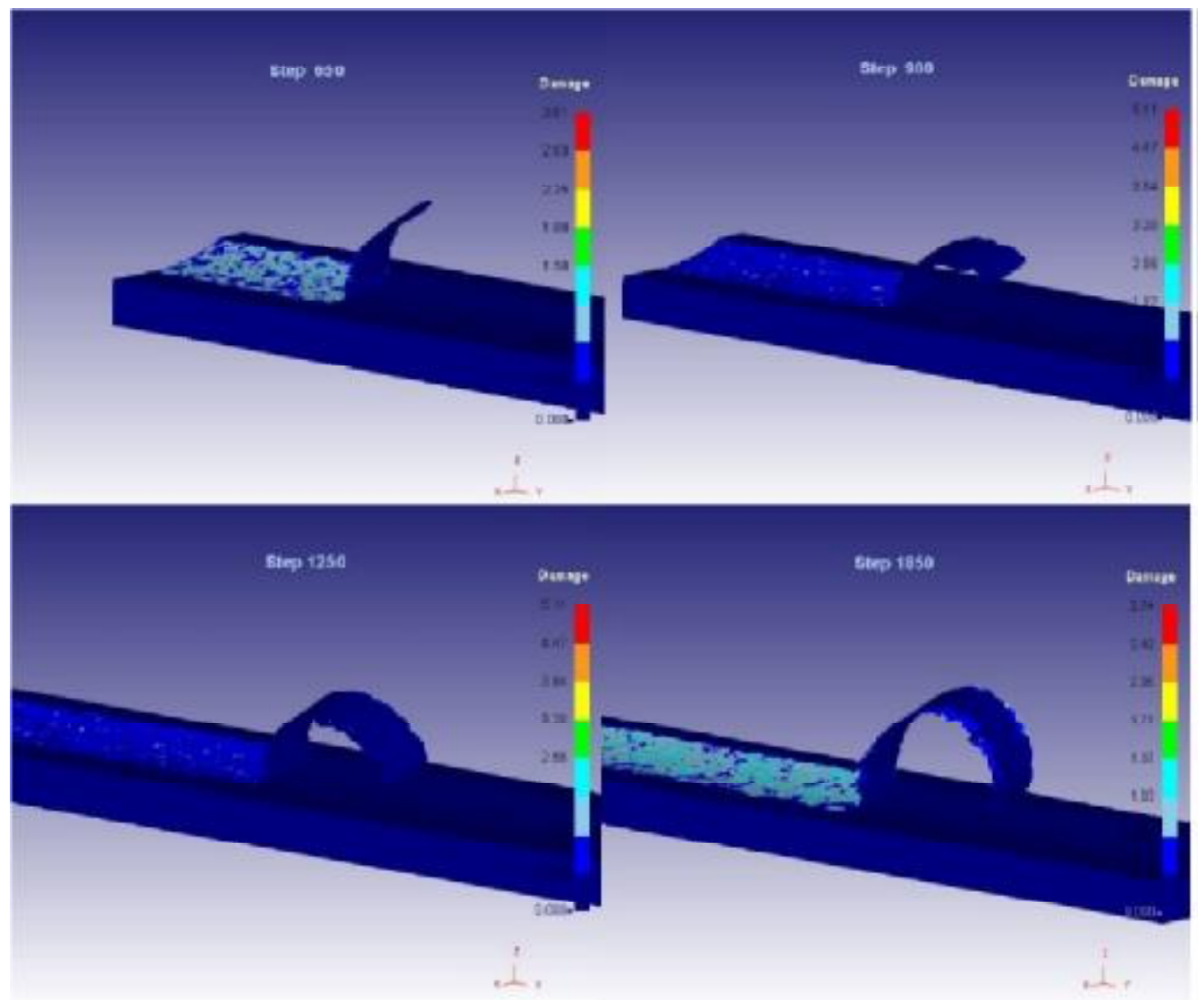

Fig. 4. Damage in machining process

Stress-effective - can be characterizes as a force acting on specific area of material. Stres is divided to two categories. Normal stress is acting perpendicular to workpiece surface and shear stress is acting in longitude direction to workpiece surface. In the fact of this total stress is characterized by three normal stresses $\sigma_{X}, \sigma_{Y}, \sigma_{Z}$ and sheer stress components $\sigma_{X Y}, \sigma_{Y X}, \sigma_{Z Y}$, $\sigma_{Y Z}, \sigma_{X Z}, \sigma_{Z X}$.

Stress can be calculated using Von Mises method:

$$
\sigma v=\sqrt{ } 12[(\sigma 1-\sigma 2) 2+(\sigma 2-\sigma 3) 2+(\sigma 3-\sigma 1) 2]
$$

Following figure (Figure 5.) shows behavior of stress in machining process of hard metal sample. Maximal stress occurs in root of the chip due to material removal on the contact area. Maximal compressive stress obtained during simulation process was $1380 \mathrm{MPa}$. During whole simulation maximal value of pressure varied towards to maximal value of compressive stress. 


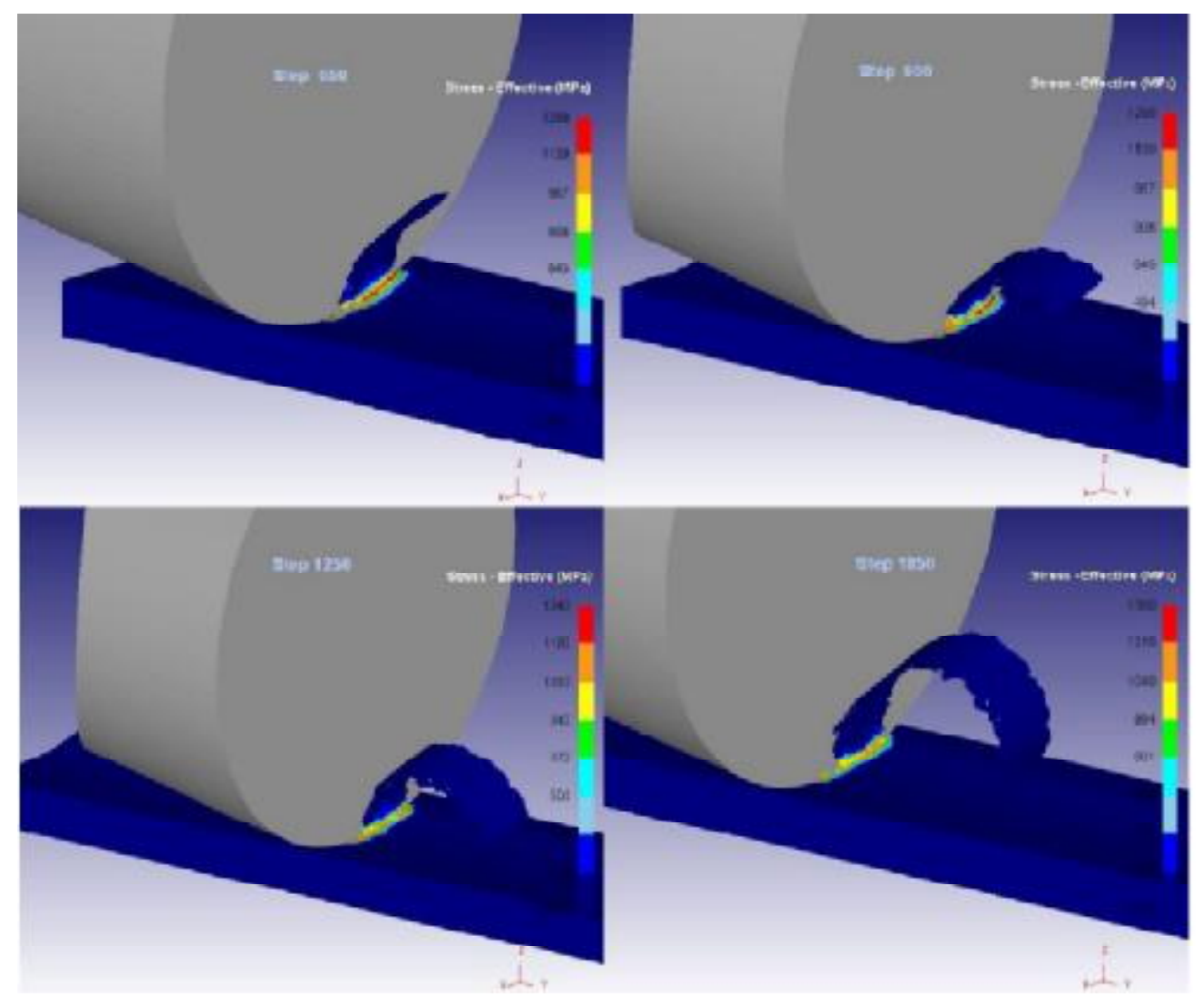

Fig. 5. Von Misses stress

\section{Temperature}

Temperature is very important factor in machining process, which affects tool durability, surface quality, heat affected zone (HAZ) and many other parameters. Simulation allows observation of temperature changes during whole machining process. Figure 6 . shows progressive increment of temperature, from starting ambient temperature $20^{\circ} \mathrm{C}$ to temperatures above $500^{\circ} \mathrm{C}$. As is evident from figure 6. majority of temperature is removed via created chip.

Three different cutting speeds were used for simulation, with constant feed rate and depth of cut. Cutting conditions are listed in table 3. Variant no. 3 represents original cutting conditions, which were used in practical conditions.

Table 3. Machining conditions

\begin{tabular}{|l|c|c|c|}
\hline & 1. Variant & 2. Variant & 3. Variant \\
\hline Cutting speed $v c\left[\mathrm{~m}_{\mathrm{min}} \mathrm{m}^{-1}\right]$ & 60 & 70 & 80 \\
\hline Feed rate $f[\mathrm{~mm}]$ & 0,25 & 0,25 & 0,25 \\
\hline Depth of cut $a_{p}[\mathrm{~mm}]$ & 1 & 1 & 1 \\
\hline
\end{tabular}



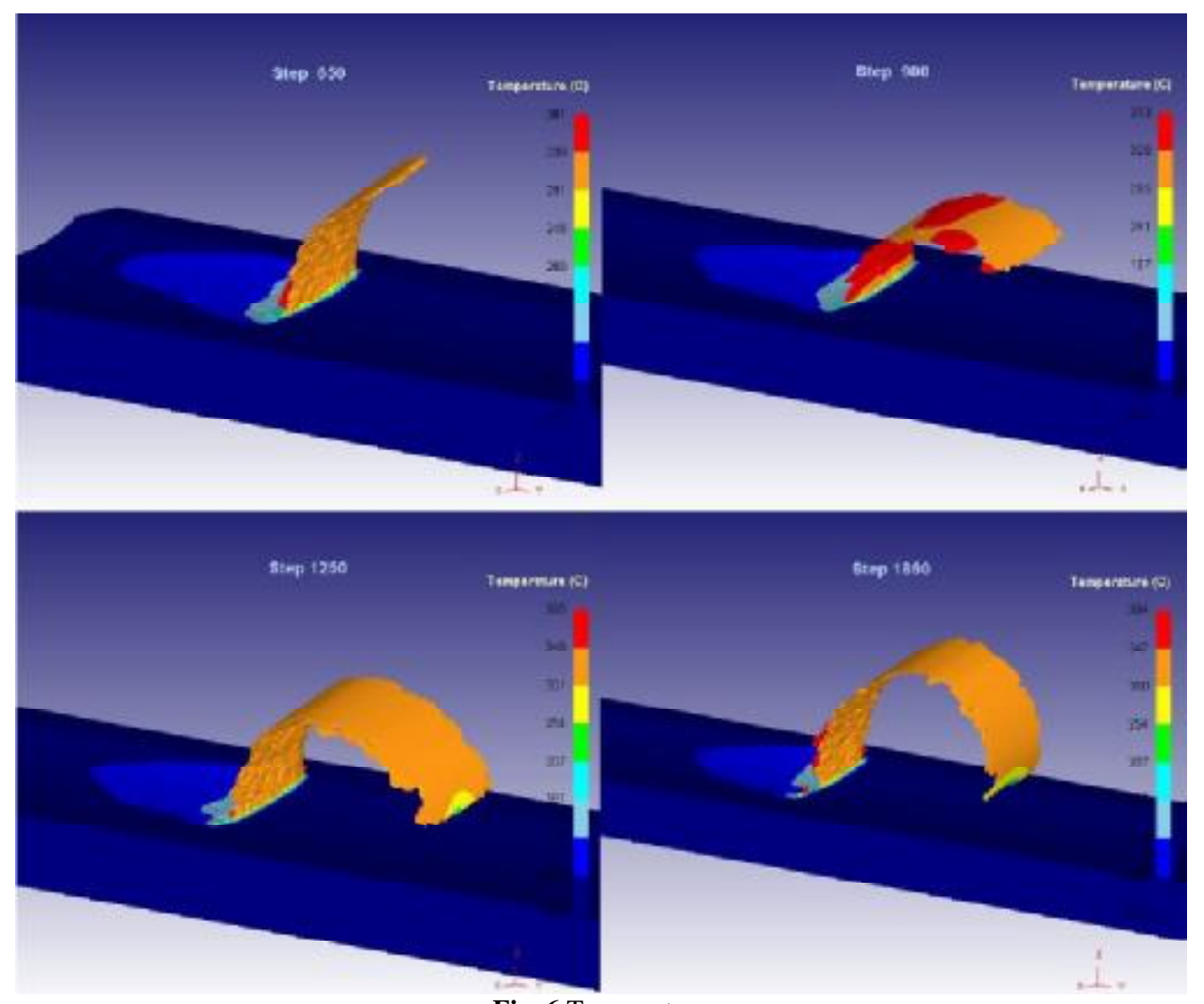

Fig. 6 Temperature

Simmulatin results shows that optimal parameter for machining hard metal samples is cutting speed from variant no.1. Using lowest cutting speed $60 \mathrm{~m} \cdot \mathrm{min}^{-1}$ results to optimal chip formation and thus lower wear rate of tool. Also stress, damage and temperature values were for variant no. 1 most appropriate for stable cutting process. Simmulated parameters will be subsequently tested in practical conditions for correctness confirmation.

\section{Conclusion}

Presented article shows simulation process of hard metal manufacturing using CBN cutting plates. Simulation was performed based on demand of manufacturing company. Results of experiment in the form of pressure values, deformation values, maximal stresses in cutting process and obtained temperatures will help to improve machining process in practical conditions and thus save money.

Acknowledgments. This paper has been elaborated in the framework of the project APVV15-0700 and VEGA1/0492/16 and in cooperation FVT TUKE with a seat in Presov and ŽP VVC Podbrezova under contract no.01/2014. 


\section{References}

[1] Hegedus, J.: Process simulation machining of carbide rolls. Diploma thesis, p. 62 (2017)

[2] Cep, R., Janasek, A., Petru, J., et al.: Surface Roughness after Machining and Influence of Feed Rate on Process. Precision Machining VII Book Series: Key Engineering Materials. pp. 341-347 (2014)

[3] Vojtko, I., Simkulet, V., Baron, P. et al.: Microstructural Characteristics Investigation of the ChipMaking Process after Machining. Operation and Diagnostics of Machines and Production Systems Operational States II book series: Applied Mechanics and Materials. pp. 344-350 (2014)

[4] Mukherjee, I., Ray, P. K.: A review of Optimization Techniques in Metal Cutting Processes, Computer and Industrial engineering. Vol. 50, pp. 15-34 (2006)

[5] Krar, S. F., Gill, A. R., Smid, A. R.: Technology of Machine Tools. 7th ed., McGraw-Hill, New York (2011)

[6] Hutyrova, Z., Orlovsky, I.: Assessment of micro-geometric and macro-geometric parameters after machining composite material with natural fibres. Operation and Diagnostics of Machines and Production Systems Operational States II book series: Applied Mechanics and Materials. pp. 267283 (2014)

[7] Zajac, J., Beraxa, P., Michalík, P., Botko, F., Pollák, M.; Simulation of Weld Elbows Hot Forming Process. International Journal of Modeling and Optimization. Vol. 6, pp. 77-80 (2016)

[8] El-Sayed, M.M., Shash, A.Y., Abd-Rabou, M.: Finite element modeling of aluminum alloy AA5083-O friction stir welding process. Journal of Materials Processing Technology. Vol. 252, pp. $13-24(2018)$ 